\title{
O USO DA CURVA ABC PARA A TOMADA DE DECISÃO NA COMPOSIÇÃO DE ESTOQUE
}

\section{THE USE OF THE ABC CURVE FOR THE DECISION MAKING IN THE STOCK COMPOSITION THE}

\author{
Bruno Teixeira dos Santos ${ }^{1}$, Cleidice Lubiana ${ }^{2}$ \\ 1 Discente do curso de graduação em Curso de Ciências Contábeis da Faculdade de Informática de Ouro \\ Preto do Oeste - UNEOURO. \\ 2 Mestra em administração pela Universidade Federal de Lavras-MG; Graduada em administração; \\ Coordenadora do curso de Administração e Professora dos cursos de Administração, Ciências contábeis e \\ Pedagogia da Faculdade de Informática de Ouro Preto do Oeste -UNEOURO.
}

*Autor correspondente: brunosadol@hotmail.com

Recebido: 07/11/2017; Aceito: 09/12/2017

\section{RESUMO}

O uso da curva $A B C$ é muito eficiente para toda organização, pois ela auxilia o gerenciamento e controle de estoques. A gestão correta de qualquer tipo de estoque é um diferencial positivo para que o administrador possa gerenciar os recursos e conter custos dentro da entidade, contribuindo com a contenção de gastos, a melhoria do gerenciamento e qualidade dos estoques. A curva $A B C$ é uma importante ferramenta gerencial que tem por função analisar e classificar os produtos que requerem uma atenção especial do gestor. Para este trabalho optou-se pela pesquisa descritiva com uso de material bibliográfico. Esse estudo tem como objetivo verificar o sistema de classificação da curva $A B C$ no gerenciamento e composição de estoques, suas formas de aplicação, sua utilização no gerenciamento dos valores monetários e quantidades disponíveis em estoque. $A$ curva $A B C$ é baseada na teoria de Pareto, na qual são divididos os estoques em classes A, B e C. Os resultados, apresentam melhor controle no gerenciamento para a diminuição de perdas e/ou manutenção de estoques em excesso. $O$ estudo mostra que a curva $A B C$ influencia diretamente na tomada de decisão da composição de estoque, mantendo estoques mais coerentes, reduzindo desperdícios e fazendo com que o administrador faça investimentos inteligentes, visando a lucratividade.

Palavras-chave: Curva ABC. Gestão de estoques. Definição de prioridade de estoque.

\section{ABSTRACT}

The use of the $A B C$ curve is effective for every company as it assists inventory management and control. Correct management of any type of inventory is a positive differential so that the administrator can manage the resources and contain costs within the entity, contributing to the containment of expenses, the improvement of the management and quality of the stocks. The $A B C$ curve is an important management tool used to analyze and classify products that deserve special attention from the manager. For this work we opted for the descriptive research using bibliographic material. This study aims to verify the classification system of the $A B C$ curve in the management and composition of inventories, their forms of application, their use in the management of monetary values and quantities available in stock. The ABC curve is based on the Pareto theory, in which stocks are divided into classes A, B and C. The results, present better control in the management to reduce losses and / or maintenance of excess stocks. The study shows that the $A B C$ curve directly influences inventory composition decision making, keeping inventories more consistent, reducing waste and making the manager invest wisely for profitability.

Keywords: $A B C$ curve. Inventory management. Inventory priority setting. 


\section{ARTIGO DE REVISÃO I review article}

\section{INTRODUÇÃO}

$O$ uso da curva $A B C$ para a tomada de decisão na composição de estoque é essencial para que a empresa seja mais eficaz na organização de seus produtos em estoques. Com o sistema $A B C$ podem-se obter diversas vantagens financeiras e na organização de estoque. Por meio deste sistema é possível separar os produtos em estoque por valor e quantidade. Com isso, torna-se uma ferramenta importante para o administrador, a partir dela é possível à identificação e distinção dos itens em estoque.

Para Viana [1] é possível a separação do estoque em classes A, B e $\mathrm{C}$, isso depois de ordenados pela importância relativa. Arnold [2] separa os itens em porcentagem, sendo assim: classe (A) representa os $20 \%$ dos estoques de alto valor chegando até $80 \%$ do valor de investimento total do estoque. Os itens de classe (B) são aqueles de itens médio representando $30 \%$ do estoque da empresa que possuem um valor de investimento de $15 \%$. Já os itens de classe (C) possuem um baixo valor e possuindo cerca de $50 \%$ de quantidade em estoque e aproximadamente $5 \%$ da utilização em valores monetários.

Pode ser feita a curva para melhor tomada de decisão na formação de estoque, entretanto, não é necessário que esta seja construída, basta seguir alguns procedimentos: para cada produto, é determinado a aplicação monetária que ele acarreta, e depois ordenam-se os produtos do maior para o menor investimento, calcula-se a porcentagem que cada item representa no investimento total e as porcentagens acumuladas, faz-se a separação em classes $A, B$ e $C$ de forma quantitativas [3].

Moreira [3] e Dias [4] asseguram que é possível identificar que os itens do estoque de uma empresa, ao utilizar o método $A B C$, são divididos e separados pelo seu valor de investimento, quantidade e sua importância para a organização, para melhor facilitar a tomada de decisão, para o controle de estoque da administração, definir seus modos de vendas, verificar quais tipos de produtos tem prioridade para a produção e outros problemas usuais na empresa.

Com as mudanças diante do crescente avanço tecnológico dos últimos tempos e do consequente aumento da competitividade e novos desafios enfrentados pelas empresas, surgiu a necessidade do aumento da qualidade, da economia do tempo e da redução dos custos a fim de evitar a perda de espaço no mercado. As dificuldades encontradas em gerenciar estoques estão cada vez mais presentes. Em algumas empresas, principalmente de pequeno porte, por não 


\section{ARTIGO DE REVISÃO | review article}

ter conhecimento ou acesso a ferramentas capazes de proporcionar uma melhor decisão para composição de estoque, essa dificuldade se acentua. Desta maneira questiona-se como o uso da curva $A B C$ poderá auxiliar nas tomadas de decisões na composição de estoque das organizações?

Ao elaborar a curva $A B C$ dos produtos em estoque, identificar a sua classificação e verificar quantidades de itens, os maiores e menores pesos na composição, pode-se inferir o total dos recursos financeiros aplicados no estoque e assim obter os melhores resultados a partir das análises e tomada de decisão referente à gestão de estoque.

O objetivo deste trabalho é demonstrar o uso da curva $\mathrm{ABC}$ como auxiliar na tomada de decisão na composição de estoque das organizações, reduzindo custos, verificando quais itens são encarregados por maior, intermediário e menor investimento e peso na gestão do estoque.

1.1. EVOLUÇÃO DO CONCEITO E SISTEMA DE CLASSIFICAÇÃO DE STOQUE PELO MÉTODO CURVA ABC E A DETERMINAÇÃO DE PRIORIDADES.

O sociólogo, economista, engenheiro e italiano, Vilfredo Pareto
(1848-1923), muito antes do aparecimento das pesquisas econométricas, ao elaborar um estudo de distribuição de renda e riqueza da população local, em 1897, descobriu, nos países capitalistas e também em locais onde reinavam os senhores feudais ou capitalismo nascente, que 0 maior segmento da renda nacional concentrava-se em uma pequena parte das pessoas, ou seja, a maior porcentagem monetária estava nas mãos da menor quantidade de indivíduos [1].

Pareto observou que $80 \%$ da riqueza local estavam concentrados com $20 \%$ da população. Com base nas características dos diferentes países estudados, anotou uma série de informações sobre o número de pessoas pertencentes à pesquisa em diferentes faixas de renda recebida [1]. Em seguida, após obter os dados específicos, traçou um gráfico, marcando as diferentes faixas de renda no eixo das abscissas (horizontal) e, no eixo das ordenadas (vertical), o número de pessoas que recebiam rendas iguais ou superiores as de cada faixa. Através desse gráfico ele observou que 80 a $90 \%$ da população pertencem a duas ou três classes inferiores. Concluiu que qualquer medida que atingisse duas ou três classes predominantes estaria englobando 0 grosso da população. Assim nasceu o diagrama de Pareto [1]. 


\section{ARTIGO DE REVISÃO I review article}

O princípio de Pareto afirma que, para muitos eventos, aproximadamente $80 \%$ dos efeitos vêm de $20 \%$ das causas. Essa constatação de concentração de determinada variável descoberta por Vilfredo Pareto, na época, ficou conhecida como Lei de Pareto [1, 5].

Pozo, Viana [1] e Arnold [2] observam que o princípio $A B C$ se baseia na constatação de que uma pequena quantidade de estoque domina os maiores recursos financeiros e são responsáveis pelos melhores resultados atingidos na maioria das situações.

No conceito de Dias [4] a curva $A B C$ é um importante instrumento para o administrador, porque ela permite identificar aqueles itens que justificam maior atenção e tratamento quanto a sua administração. Tal instrumento é obtido através da ordenação dos produtos conforme a importância relativa do mesmo.

Com auxílio da teoria de Pareto, a empresa General Eletric, americana, adaptou o princípio de Pareto ao universo dos materiais, mais concentrado no controle e gerenciamento de estoque, com a denominação curva ou classificação $A B C$, instrumento que serve para identificar itens quem requerem atenção e tratamento diferenciados em seu controle [1].

Moreira [3] afirma que o nome curva $A B C$ é relativo ao fato de poder ser dividida em três grandes partes ou classes - A, B e C. Determinados itens de estoque em uma empresa têm custos de manutenção maior que outros, deste modo são interessantes pensar em alguma forma de classificar esses produtos por algum critério de importância, de modo que se possam definir quais itens merecem maior atenção e alocação de recursos em sua gestão [6].

A curva $A B C$ pode ser definida como uma técnica para classificar os itens de estoque de determinada empresa dividindo-os em três grupos distintos, com base no seu valor financeiro total anual [6]. O objetivo da técnica é definir grupos para os quais diferentes sistemas de controle de estoque serão mais apropriados, resultando um controle mais eficiente.

Arnold [2], Pozo [5] e Moreira [3] certificam que a lei de Pareto aplicada à administração de estoques, geralmente, tem uma relação entre a porcentagem de itens e a porcentagem da utilização anual dos valores e descreve da seguinte forma a curva $A B C$ :

- Itens de classe A são os mais importantes no estoque e devem receber toda a atenção no primeiro momento do estudo. São nesses produtos que devem ser tomadas as primeiras decisões sobre os dados obtidos em razão de seu 


\section{ARTIGO DE REVISÃO | review article}

valor monetário. Em média $80 \%$ do valor monetário total e $20 \%$ da quantidade em estoque.

- Itens de classe B são os intermediários e deverão ser tratados logo depois das medidas referentes aos itens da classe $A$, são os segundos em importância. Geralmente os dados classificados correspondem a $15 \%$ do valor monetário e $30 \%$ do estoque total.

- Os itens de classe C são os de menor importância, mesmo que sejam uma quantidade de itens bem elevada. $\mathrm{Na}$ prática é responsável por um valor monetário bem inferior aos demais, fazendo com que ocupe mais espaço e tempo para a sua análise e controle. Deverão ser estudado só após os itens da classe A e B. Em geral, somente $5 \%$ do valor monetário e mais de $50 \%$ do estoque integral.

Segundo Pozo [5] esses valores percentuais das divisões das classes $A B C$ são orientativos e não devem ser considerados como regra geral. São baseadas nos valores e quantidades totais contido em estoque. São percentagens aproximadas e não devem ser tomadas como absolutas [2].

Viana [1] e Dias [4], assim como Arnold [2], Pozo [5] e Moreira [3], separam os itens em classes da curva $A B C$, após ordenados pela importância relativa. $E$ as definem da seguinte forma:

- Classe A (grupo de itens mais importantes que devem ser tratados com atenção especial pela administração) ;

- Classe B (grupo de itens intermediários entre a classe $\mathrm{A} e$ $\mathrm{C}$, demanda uma média atenção da administração);

- Classe C (grupo de itens menos importante que justificam pouca atenção por parte da organização).

Corrêa \& Corrêa [6] classificam a curva $A B C$ em três grandes grupos, sendo eles, o grupo A que são poucos itens, todavia são os responsáveis por grande parte do valor de uso total. Assim, estes devem ser os produtos que merecem a maior atenção gerencial, para os quais vale mais manter um controle de estoque eficaz e rigoroso. O grupo B, são os itens intermediários, um pouco menos rigoroso do que os de classe $\mathrm{A}$. O grupo $C$, que são responsáveis por uma parcela muito menor do valor total monetário, mas com valor elevado de estoque, não necessitam de muita atenção gerencial.

Os benefícios do esforço gerencial para controlar os estoques dos itens de classe A são muito maiores do que os benefícios de um esforço gerencial similar para manter estoques mais baixos 
de itens $C$, que não trazem tanto retorno monetário [6].

Os itens com movimentos de valores monetários particularmente altos demandam um controle mais cuidadoso, enquanto aqueles com baixa movimentação de valor não precisam ser controlados tão rigorosamente quanto aos de valores mais elevados. Geralmente, uma pequena proporção dos itens totais contido no estoque vai representar uma grande proporção do valor monetário em estoque da administração [7].

A utilização da classificação $A B C$ é muito vantajosa, pois pode-se reduzir as imobilizações em estoque sem prejudicar a segurança, porque ela controla mais rigidamente os produtos em estoque da classe A e, sem muita rigidez, os itens de classe $C$ [5].

Pozo [5] e Moreira [3] ainda afirmam que a metodologia de classificação $A B C$ pode ser aplicada em qualquer caso de classificação de itens, quaisquer naturezas, pode, também, ser usada em diferentes unidades de medidas, a saber: peso, tempo, volume, custo unitário entre outras.

Corrêa \& Corrêa [6] argumentam que se devem usar sistemas mais caros que permitem um controle mais rigoroso e eficiente para controlar os itens em estoque que são mais importantes, enquanto 0 uso de sistemas mais baratos, fáceis de se operar e menos rigorosos devem ser usados para os itens com menor importância.

Segundo Viana [1] a metodologia do cálculo da curva $A B C$ é um fundamento que pode ser aplicado a quaisquer situações em que seja possível estabelecer prioridades, por exemplo, ter uma tarefa a cumprir que seja mais importante das demais tarefas, uma obrigação com mais significância que outra, de forma que a soma de algumas partes dessas tarefas ou obrigações de importância elevada represente, provavelmente, uma grande parcela das obrigações totais.

Nesse sentido, mais voltada para a área administrativa, a curva $A B C$ tornouse de uma utilidade significativa e ampla em diversos setores que se necessita tomar decisões envolvendo quantidades elevadas de dados e estoques. Não só é usada para controle de estoques como também em produções, vendas, salários e outros [5].

Normalmente, uma empresa mantém centenas ou milhares de itens em estoque. Gerenciar todo o estoque da organização com a mesma atenção e os mesmos métodos pode ser bastante custoso, obrigando a entidade a encontrar alguma forma de dar atenção diferenciada a certos itens estocados. Para que se tenha um controle melhor e menos custoso é necessário que se 
adote um critério, que permita distinguir claramente a importância de uma mercadoria em estoque da outra, por isso é útil classificar os itens de acordo com sua importância. Geralmente, essa classificação é feita pelos valores monetários anuais [2, 3].

Segundo Slack e Johnston [7] em qualquer estoque que tenha mais de um item armazenado, sempre, alguns serão mais importantes que os outros. Uma forma comum de discriminar diferentes itens de estoque é fazer uma lista deles, de acordo com suas movimentações de valor (sua taxa de uso multiplicada pelo seu valor individual), por isso a importância do uso da classificação $A B C$.

Arnold [2] cita, especificamente, a classificação $A B C$ no controle de estoque. $\mathrm{O}$ autor define que o estoque é controlado pelos itens individuais. E para esse controle são feitas duas perguntas: qual importância tem aquele determinado produto em estoque? de que forma os itens são controlados?

A resposta para as duas perguntas está na curva ou classificação $A B C$, pois ela determina a importância de cada produto em estoque e a forma como eles serão controlados pela instituição, com isso, é possível obter diferentes níveis de controle baseados na importância relativa dos itens armazenados [2].

Dias [4] fez um estudo em algumas empresas e constatou que 0 princípio $A B C$ é universal, mas existe diversas objeções ou simplesmente desculpas para não utilizá-lo em determinadas empresas ou situações. Ele citou algumas dessas objeções apresentadas pelas empresas para o não uso do princípio $A B C$ :

A) “ nunca experimentamos fazer, ou
utilizar uma classificação ABC, mas
achamos que o cliente poderá sentir-
se igualmente prejudicado pela falta
de um produto de alto valor de
utilização ou muito necessário, ou a
produção poderá ser prejudicada
tanto pela falta de uma peça
considerada irrelevante e de
pequeno valor de utilização, como
pela falta de um item de alto valor de
utilização."

Dias [4] responde a essas objeções da seguinte forma: não se deve deixar de controlar os itens $\mathrm{C}$ ou esquecê-los. Pois, a classificação $A B C$ atenua que se deve manter a maior quantidade de estoque de itens de pequeno valor de utilização. Mas, isso não significa esquecimento, 0 que resultaria no esgotamento dos itens que pertencem a classe C. Para Dias [4] a partir do momento em que existam quantidades elevadas de produtos de pequeno valor em estoque, a concentração de esforços poderá ser dirigida aos itens de grande valor de utilização, classe $A$, sem que se deixe faltar os itens de pequeno valor de uso, classe $\mathrm{C}$.

B) "já tentamos utilizar uma classificação $A B C$, mas não resultou em redução dos estoques de itens de classe $A$, muito embora os estoques dos itens de classe $\mathrm{C}$ 


\section{ARTIGO DE REVISÃO I review article}

tenham

aumentado

significativamente."

Outra vez o princípio básico da curva $A B C$ foi ignorado, isto é, dedica-se pouquíssima atenção gerencial aos produtos de classe $\mathrm{C}$ em benefício dos itens de maior valor. Isso, com certeza, levarão a elevação desnecessária dos estoques de uma classe, sem benefício para empresa [4].

C) "já fizemos a classificação $A B C$ e passamos a controlar todos os itens de classe $\mathrm{C}$ por meio de um sistema de controle visual de revisão mensal. Após análise, achamos desnecessário revisar com periodicidade mensal, ainda que só visualmente, aqueles itens que somente vão ser consumidos uma ou outra vez durante o ano."

A curva $A B C$ recomenda que se faça um controle menos rigoroso na classe C, porém não deve ser visual, que não exige registros ou feitos com controle mensal frequentemente. Mas sim, esses sistemas devem ser controlados através de registros, e não com um sistema visual periódico [4].

D) "fizemos uma classificação $A B C$ e eliminamos todos os itens da linha $C$. Quase falimos."

Dias [4] afirma que a curva $A B C$ não é um método a ser utilizado para decidir tirar produtos de linha ou de estoque. Por exemplo, um automóvel: o motor e o câmbio seriam da classe $\mathrm{A} e$ os parafusos como itens da classe $\mathrm{C}$. Isso significa que se poderiam eliminar os parafusos, itens da classe C? De maneira nenhuma. A curva $A B C$ diz quem é quem, mas não diz o que fazer. Todos os itens do estoque devem ser controlados, o que se preconiza no sistema $A B C$ é a atenção dada aos itens que correspondem aos maiores valores monetários envolvidos no estoque das empresas, para que se tenha uma tomada de decisão relativa a controle de estoque com maior clareza e assertividade.

Arnold [2] na sequência observa que no controle da classificação $A B C$ devem ser utilizados diferentes controles com as diferentes classificações:

- Itens de classe A: a mais elevada prioridade possível neste item. Tem que ter um controle cerrado, como registros completos, revisões regulares e frequentes por parte da organização, agilização e revisões das previsões de demanda.

- Itens de classe B: média prioridade. Deve haver um controle normal, mas sem deixar de ser bom. Registros, atenção regular e processamento normal.

- itens de classe C: pouca prioridade. Controle bem simples e barato, porém tem que garantir que os itens sejam suficientes. Fazer pedidos em quantidades maiores e manter um estoque seguro. Não é necessário registro 


\section{ARTIGO DE REVISÃO | review article}

completo ou normal, mas um simples registro já é aceitável.

A determinação de prioridade dos itens de estoque traz para o gestor maior clareza para determinação dos itens de maior relevância monetária. $\mathrm{O}$ valor investido em estoque deve refletir a necessidade de uso do item na empresa. Se um número pequeno de itens representa um valor alto em termos monetários é fundamental ter maior atenção sobre esses, dado que o volume financeiro relativo a esses produtos pode comprometer a gestão financeira se houver falha no controle que serve de embasamento para a tomada de decisão.

A utilização do princípio da curva $A B C$ traduz, no controle dos itens de estoque, a escala de importância monetária relativa ao total de investimento em estoque, mostrando onde se encontra o maior volume monetário e definindo as prioridades na tomada de decisão. Cabe ao gestor definir, juntamente com os outros controles gerenciais o modo como se dará o controle, verificar os itens que compõem a base de sua matéria-prima, peças de manutenção e outras necessidades, definindo quais os pontos que influenciam para que a empresa obtenha o melhor resultado possível na administração de seu estoque, possibilitando obter informações estratégicas para realizar compras de mercadorias e gerenciar o estoque com mais eficácia.

\section{MATERIAIS E MÉTODOS}

Os materiais utilizados no referido trabalho foram: livros de autores renomados e relativo ao tema curva $A B C$, encontrados na biblioteca da faculdade UNEOURO (Faculdade de Ouro Preto do Oeste), e também em artigos científicos publicados e disponíveis via internet. Os materiais separados e levantados foram lidos, estudados e analisados para que toda a informação fosse repassada ao leitor. O método aplicado foi a pesquisa bibliográfica referente ao tema proposto para correta coleta de dados e melhor fortalecer o assunto explicado.

A metodologia é um processo de pesquisa, utilizada para realizar o estudo de um determinado tópico, os quais ensinam como fazê-la de forma correta. Ela é uma disciplina normativa estabelecida como o estudo sistemático e lógico dos princípios que gerem a pesquisa científica, desde suposições básicas até técnicas de averiguação. Pesquisa é um composto de ações, onde procura-se buscar soluções para um problema, por base de processos racionais e sistemáticos.

Para Gil [9] a pesquisa tem uma natureza pragmática, e é um processo formal e sistemático de desenvolvimento de método científico. $O$ objetivo 


\section{ARTIGO DE REVISÃO I review article}

fundamental da pesquisa é descobrir resposta para problemas mediante empregos de procedimentos científicos.

A metodologia de pesquisa diz respeito aos métodos utilizados para se chegar ao objetivo de estudo. Parra e Santos [10] dizem que logo depois que se define assunto a ser estudado, devese determinar o caminho a ser seguido, ou seja, quais elementos são necessários e como utilizá-los para que os objetivos sejam atingidos. "A forma como utilizar os recursos disponíveis, apresentação dos objetivos e procedimento do pesquisador para atingir $O$ resultado esperado denomina-se metodologia". A partir desses conceitos $e$ atento para às característica da pesquisa, optou-se pela pesquisa bibliográfica, com levantamento de referencial teórico relativo ao conteúdo.

\section{RESULTADOS E DISCUSSÕES}

\subsection{A ADMINISTRAÇÃO DE ESTOQUE E A CONSTRUÇÃO DA CURVA ABC}

Para Pereira [11] a gestão de estoque é necessário a classificação de itens, determinação de uso e valor monetário. A curva $A B C$ é um dos métodos utilizados para classificação e controle de estoque, sendo necessária a sua construção e aplicação para uma melhor gestão.
Arnold [2] diz que a curva $A B C$ pode ser construída passo a passo. Em primeiro lugar devem ser estabelecidas as características (valores monetários, geralmente, ou outros critérios, como a falta de materiais) do produto que influenciam o resultado da administração de estoques. Em seguida, classificam-se os itens com base no critério escolhido. Por fim, aplica-se o grau de controle proporcional à importância do grupo.

Para Arnold [2] há fatores que afetam a importância de um item, como: utilização anual em valores monetários, o custo da unidade e a escassez de material. Para o autor, a exemplificação mais simples seria com a utilização anual em valores monetários.

Segundo Pozo [5], para a montagem da curva $A B C$, é necessário o processo de quatro passos, sendo eles: (1) inicialmente deve-se levantar todos os dados dos itens com os quais há problemas e precisam ser resolvidos, isto é, levantar quantidade, preços unitários e preço totais; (2) em seguida, é necessário que se faça uma tabela e coloque todos os itens em ordem decrescente de preço totais e sua somatória total. A tabela referida deverá ter as seguintes colunas: item, nome ou numero da peça, preço unitário, preço total do item, preço acumulado e percentagem; (3) o próximo passo é dividir cada valor total de cada item pela 


\section{ARTIGO DE REVISÃO I review article}

somatória total de todos os itens e colocar a razão obtida em sua devida coluna; (4) por fim, devem-se dividir todos os itens em classe A, B e C, de acordo com a prioridade e tempo disponível para tomar a decisão sobre o problema.

De acordo com Corrêa \& Corrêa [6] a aplicação da curva ou classificação ABC deve-se seguir oito etapas: 1Determinar a quantidade total utilizada no ano anterior de cada item armazenado; 2- Determinar o custo médio de cada um dos itens em estoque, fazendo uso de moeda nacional; 3- Calcular o custo anual total de uso de cada item, e logo após multiplicar o custo médio do item, levantado em dois, pela quantidade correspondente utilizada, levantada em um; 4- Ordenar todos os itens em valor decrescente do valor estabelecido em 3; 5- Calcular os valores acumulados de valor de uso para toda a lista, na ordem definida em 4; 6- Calcular os valores acumulados determinados em $5 \mathrm{em}$ percentuais, isso em relação ao valor total acumulado de valor de uso para o total dos itens; 7. Desenhar os valores, percentuais, em um gráfico; 8. Definir as três regiões conforme a inclinação da curva resultante: região $A$, de grande inclinação; região $B$ de média inclinação; região $C$, de pequena inclinação.

Figura 1: Demonstração da Curva ABC

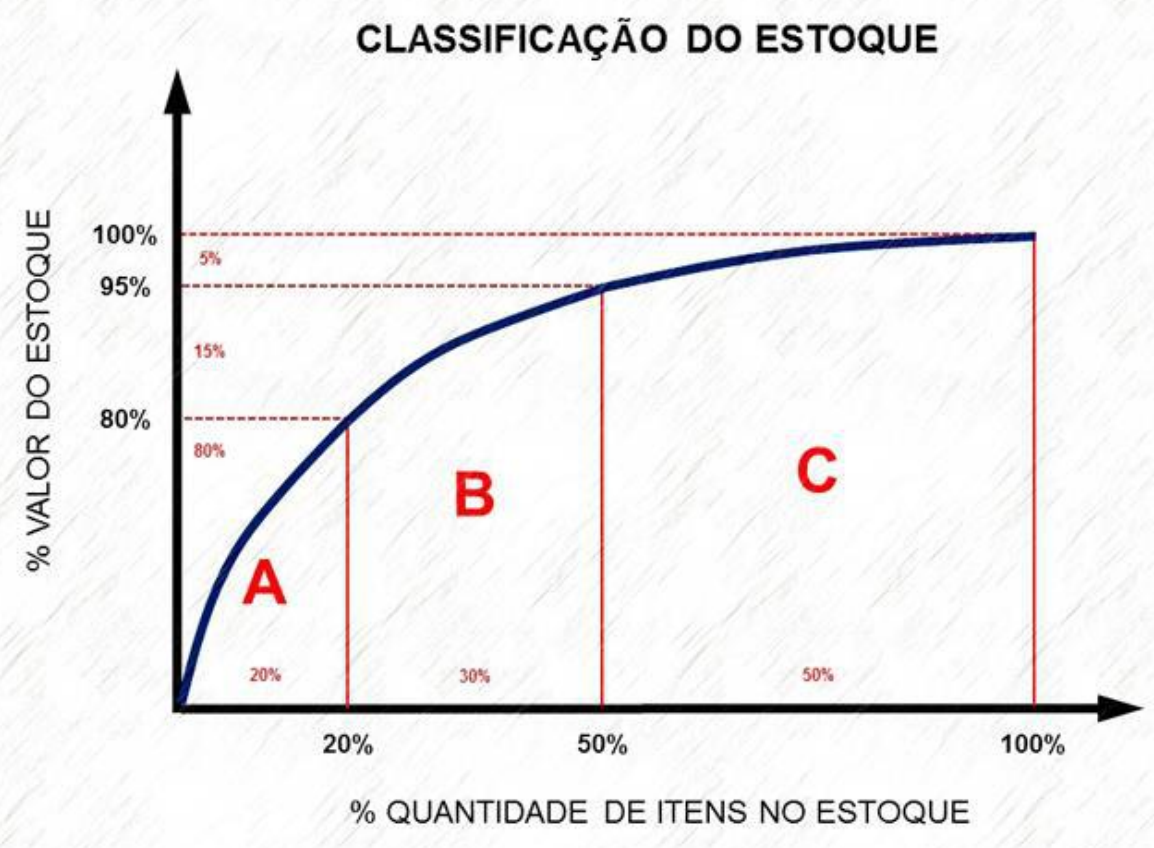

Fonte: SOARES, 2015. 


\section{ARTIGO DE REVISÃO I review article}

Não há necessidade da construção da curva $A B C$ para se determinar as regiões ou classificações A, B e C. A partir de uma série de itens que se quer classificar, podem ser seguidos os procedimentos: 1ํdeterminar o investimento de cada item; $2^{\circ}-$ ordenar do maior para o menor investimento; $3^{\circ}$ - calcular a percentagem que cada item representa no investimento total e, em seguida, as percentagens acumuladas; $4^{\circ}$ - fazer as divisões em classes A, B e C [3].

Para Arnold [2] é bem simples o procedimento de classificação por utilização anual em valores monetários, sendo a sequência: $1^{\circ}$ - determinar a utilização anual de cada produto, 2fazer a multiplicação da utilização anual para cada item pelo seu respectivo custo, para que se obtenha sua utilização total anual em valores monetários, $3^{\text {-}}$ - listar os itens de acordo com a sua utilização anual em valores monetários, 4ํ- calcular a utilização anual em valores acumulados e percentagem acumulada dos itens, $5^{\circ}$ o último procedimento é examinar a distribuição da utilização anual e classificar os produtos em estoque nos grupos $A$, B e $C$, todos com base na percentagem de utilização anual.

A seguir será demonstrado como pode ser aplicada a curva $A B C$ em uma empresa, com a utilização de um exemplo, considerando que uma indústria fabrica dez itens, sua utilização, custo por unidade e a utilização anual em valores monetários serão demonstrados nas tabelas abaixo:

Tabela 1- Cálculo da utilização anual em valores monetários de cada item.

\begin{tabular}{c|c|c|c}
\hline $\begin{array}{c}\text { Número da } \\
\text { peça }\end{array}$ & $\begin{array}{c}\text { Utilização por } \\
\text { unidade }\end{array}$ & Custo por unidade & $\begin{array}{c}\text { Utilização anual em valores } \\
\text { monetários }\end{array}$ \\
\hline 1 & 1.100 & 2 & 2.200 \\
\hline 2 & 600 & 40 & 24.000 \\
\hline 3 & 100 & 4 & 400 \\
\hline 4 & 1.300 & 1 & 6.300 \\
\hline 5 & 100 & 60 & 250 \\
\hline 6 & 10 & 25 & 200 \\
\hline 7 & 100 & 2 & 3.000 \\
\hline 8 & 1.500 & 2 & 400 \\
\hline 9 & 200 & 2 & 500 \\
\hline 10 & 500 & 1 & $\$ 38.250$ \\
\hline Total & 5.510 & & \\
\hline
\end{tabular}

Fonte: Arnold [2], p. 268.

A partir da primeira tabela, elabora-se a segunda para que se consiga uma lista de itens de acordo com sua utilização anual em valores monetários, em seguida, o cálculo da utilização anual em valores monetários acumulados e a percentagem acumulada dos itens e finalizando, serão agrupados os itens em uma classificação ABC [2]. 


\section{ARTIGO DE REVISÃO I review article}

Tabela 2- Listas dos itens, utilização anual em valores monetários acumulados e as percentagens e agrupamento dos itens em classificação ABC.

\begin{tabular}{c|c|c|c|c|c}
\hline № da peça & $\begin{array}{c}\text { Utilização anual } \\
\text { em valores } \\
\text { monetários }\end{array}$ & $\begin{array}{c}\text { Utilização } \\
\text { acumulada em } \\
\text { valores } \\
\text { monetários }\end{array}$ & $\begin{array}{c}\text { \% acumulado de } \\
\text { utilização em } \\
\text { valores } \\
\text { monetários }\end{array}$ & $\begin{array}{c}\text { Percentagem } \\
\text { acumulada de itens }\end{array}$ & Classe \\
\hline 2 & 24.000 & 24.000 & 62,75 & 10 & $\mathrm{~A}$ \\
\hline 5 & 6.000 & 30.000 & 78,43 & 20 & $\mathrm{~A}$ \\
\hline 8 & 3.000 & 33.000 & 86,27 & 30 & $\mathrm{~B}$ \\
\hline 1 & 2.200 & 35.200 & 92,03 & 40 & $\mathrm{~B}$ \\
\hline 4 & 1.300 & 36.500 & 95,42 & 50 & $\mathrm{~B}$ \\
\hline 10 & 500 & 37.000 & 96,73 & 60 & $\mathrm{C}$ \\
\hline 9 & 400 & 37.400 & 97,78 & 70 & $\mathrm{C}$ \\
\hline 6 & 400 & 37.800 & 98,82 & 80 & $\mathrm{C}$ \\
\hline 7 & 250 & 38.050 & 99,48 & 90 & $\mathrm{C}$ \\
\hline
\end{tabular}

Fonte: Arnold [2], p. 268.

Ao elaborar a construção da curva $\mathrm{ABC}$, com os diferentes esquemas utilizados nas construções das mesmas, podem ser resumidas sob a forma de segmentos, como se vê no quadro
1. Essa apresentação pretende facilitar 0 entendimento e a confecção da classificação ABC, sem deixar de considerar os outros aspectos [4].

\section{Quadro 1- Modelo para confecção da curva ABC}

\begin{tabular}{|l|l|}
\hline 1 & $\begin{array}{l}\text { Necessidade da curva ABC } \\
\text { Discussão preliminar } \\
\text { Definição dos objetos }\end{array}$ \\
\hline 2 & $\begin{array}{l}\text { Verificação das técnicas para análise } \\
\text { Tratamento de dados } \\
\text { Cálculo manual ou eletrônicos }\end{array}$ \\
\hline 3 & $\begin{array}{l}\text { Obtenção da classificação: classe A, classe B e classe C sobre a ordenação efetuada } \\
\text { Tabelas explicativas e traçados do gráfico ABC }\end{array}$ \\
\hline 4 & Análise e conclusões \\
\hline 5 & Providências e decisões \\
\hline
\end{tabular}

Fonte: Dias [4], p. 75.

Os devidos cuidados deverão ser tomados na fase de verificação e levantamento dos dados a serem utilizados na elaboração da curva $A B C$, isto é, ter pessoas treinadas e preparadas para fazer o levantamento, formulários para coleta de dados, normas e rotinas [4].

A coleta correta dos dados é de suma importância para a consistência das conclusões da curva ABC, principalmente quando estes dados envolvem números elevados. É necessário fazer uma pró-análise após o registro de uma amostra de dados para aferir a necessidade de pressupostos, arredondamentos e averiguação de dados, para que se possam padronizar as normas de registros. A seguir, dentro das conformidades, do número de pessoas disponíveis e, também, os equipamentos (manual ou eletrônico) 


\section{ARTIGO DE REVISÃO I review article}

disponíveis, devem ser programados a empreitada de fazer os cálculos para a composição da curva ABC [4].

Dias [4] observa que para a definição da classe $A, B$ e $C$ os itens são divididos em porcentagens com relação à quantidade de estoques disponíveis. Em regra, são colocados, no máximo, 20\% dos itens na classe $A, 30 \%$ na classe $B$ e os $50 \%$ restantes na classe C. Mas, conforme o autor, essas percentagens poderão variar de acordo com cada caso, pois cada um tem necessidades e planejamento administrativos diferentes a serem aplicados.

Antes disso, Dias [4] declara que existe diversos critérios para ordenação dos itens, consoante o objetivo particular do estudo.

Para o exemplo, deste estudo, foi utilizado o critério de ordenação por valor consumo anual (preço unitário $x$ consumo anual), para cada produto, por meio da coleta de dados

[4].

Tabela 3- Demonstração de coleta de dados.

\begin{tabular}{c|c|c|c|c}
\hline Material & Preço unitário & Consumo anual (unid.) & Valor consumo (anual) & Grau \\
\hline A & 1 & 10.000 & 10.000 & 8 $^{\circ}$ \\
\hline B & 12 & 10.200 & 122.400 & $2^{\circ}$ \\
\hline C & 3 & 90.000 & 270.000 & $1^{\circ}$ \\
\hline D & 6 & 4.500 & 27.000 & $4^{\circ}$ \\
\hline E & 10 & 7.000 & 70.000 & $3^{\circ}$ \\
\hline F & 1.200 & 20 & 24.000 & $6^{\circ}$ \\
\hline G & 0.60 & 42.000 & 25.200 & $5^{\circ}$ \\
\hline H & 28 & 8.000 & 22.400 & $7^{\circ}$ \\
\hline I & 4 & 1.800 & 7.200 & $1^{\circ}$ \\
\hline J & 60 & 130 & 7.800 & $9^{\circ}$ \\
\hline
\end{tabular}

Fonte: Dias [4], p. 76.

Após a coleta de dados, tabela, com o ordenamento dos como pode ser visto na tabela dados. anterior, Dias [4] cria uma nova

Tabela 4 - Ordenação dos dados

\begin{tabular}{c|c|c|c|c}
\hline Grau & Material & Valor consumo & $\begin{array}{c}\text { Valor consumo } \\
\text { acumulado }\end{array}$ & $\begin{array}{c}\text { (\%) porcentagem sobre } \\
\text { o valor do consumo }\end{array}$ \\
\hline $1^{0}$ & C & 270.000 & 270.000 & 46 \\
\hline $2^{0}$ & B & 122.400 & 392.400 & 67 \\
\hline $3^{0}$ & E & 70.000 & 462.400 & 79 \\
\hline $4^{\circ}$ & D & 27.000 & 489.400 & 83 \\
\hline $5^{0}$ & G & 25.200 & 514.600 & 92 \\
\hline $6^{0}$ & F & 24.000 & 538.600 & 95 \\
\hline $7^{0}$ & H & 22.400 & 561.000 & 97 \\
\hline $8^{0}$ & A & 10.000 & 571.000 & 98 \\
\hline $9^{0}$ & J & 7.800 & 578.800 & 100 \\
\hline $10^{\circ}$ & I & 7.200 & 586.000 & \\
\hline
\end{tabular}




\section{ARTIGO DE REVISÃO I review article}

Fonte: Dias, 2009, p. 77.

Dias [4] explica que depois de obtido os dados, na tabela 3, pode-se construir a curva ABC. Para isso, é traçado um eixo cartesiano em que na abscissa (horizontal) é registrado 0 número de itens e no eixo das ordenadas (vertical) são marcadas as somas dos valores de consumo.

A técnica de montagem da curva ABC, compreende três fases distintas: (I) construção; (III) interpretação dos gráficos. Com a identificação correta de percentuais e quantidades de itens de cada classe, como também sua respectiva faixa de valores [1].

Para entender melhor o processo, Viana [1] elaborou uma tabela com um rol de dez itens de uma empresa fictícia. Tal tabela traz uma relação anual de materiais utilizados pela empresa.

elaboração de tabela mestra; (II)

Tabela 5 - Relação anual de materiais utilizados pela empresa

\begin{tabular}{l|l|l|l}
\hline Material & $\mathrm{R} \$$ preço unitário & Consumo anual- unidades & Valor do consumo anual, em R\$ \\
\hline X01 & 25,00 & 200 & $5.000,00$ \\
\hline X02 & 16,00 & 5.000 & $80.000,00$. \\
\hline X03 & 50,00 & 10 & 500,00 \\
\hline X05 & 100,00 & 100 & $10.000,00$ \\
\hline X06 & 0,15 & 200.000 & $30.000,00$ \\
\hline X07 & 0,01 & 100.000 & $1.000,00$ \\
\hline X08 & 8,00 & 1.000 & $8.000,00$ \\
\hline X09 & 2,00 & 20.000 & $40.000,00$ \\
\hline X10 & 70,00 & 10 & 700,00 \\
\hline
\end{tabular}

Fonte: Viana [1], p. 66

No desenvolvimento da tabela mestra para a construção da curva $A B C$, Viana [1], com referência à tabela anterior, coloca em ordem em uma nova tabela o total do consumo de forma decrescente dos valores para que se obtenha o total do consumo acumulado e depois determina as razões com relação ao valor total do gasto acumulado.

Tabela 6- Tabela mestra para a construção da curva ABC.

\begin{tabular}{l|l|l|l}
\hline \multicolumn{1}{c|}{ Material } & $\begin{array}{c}\text { Valor do consumo anual } \\
(\mathrm{R} \$)\end{array}$ & $\begin{array}{c}\text { Valor do consumo } \\
\text { acumulado, em } \mathrm{R} \$\end{array}$ & $\begin{array}{c}\text { \% sobre o valor total } \\
\text { acumulado }\end{array}$ \\
\hline X02 & $80.000,00$ & $80.000,00$ & 45.58 \\
\hline X08 & $40.000,00$ & $120.000,00$ & 68.37 \\
\hline X05 & $30.000,00$ & $150.000,00$ & 85.47 \\
\hline X04 & $10.000,00$ & $160.000,00$ & 91.16 \\
\hline X07 & $8.000,00$ & $168.000,00$ & 95.72 \\
\hline X01 & $5.000,00$ & $173.000,00$ & 98.57 \\
\hline X06 & $1.000,00$ & $174.000,00$ & 99.14 \\
\hline X03 & 700,00 & $174.700,00$ & 99.54 \\
\hline X10 & 500,00 & $175.200,00$ & 99.82 \\
\hline
\end{tabular}

Fonte: Viana [1], p. 67. 


\section{CONSIDERAÇÕES FINAIS}

O desenvolvimento do presente trabalho possibilitou uma análise preliminar de estudos a respeito da curva ABC por meio de embasamento teórico, com os principais conceitos de autores relativos ao gerenciamento e composição de estoques com o auxílio do sistema curva $A B C$. Partindo da necessidade que toda organização deve ter o controle e a classificação dos seus itens em estoques, para que 0 administrador possa gerir com segurança, rentabilidade e diminuir o custo da entidade.

A classificação de itens em A, B e C mostra-se de suma importância para que os gestores possam dedicar-se e dar mais atenção a produtos estocados que merecem um cuidado mais afinco por causa do seu valor monetário elevado.

Foi possível perceber que o critério de classificação $A B C$ tem um conceito simples e é um sistema de fácil utilização e aplicação em qualquer tipo de organização porque pode ser separado os itens em classe $A, B$ e $C$ através de controle simples ou sistemas operacionais. $O$ trabalho permitiu a visualização da importância da curva $A B C$ no gerenciamento e composição de estoque para as empresas, e sua correta aplicação e utilização podem influenciar no resultado econômico da entidade.
A curva $A B C$ é um importante instrumento estratégico para $\mathrm{O}$ gerenciamento e composição de estoque. É possível identificar os itens em estoque que necessitam de um controle mais severo e atencioso com a classificação $A B C$, os quais representam um montante elevado, chegando a constituir $80 \%$ do valor monetário de todo o estoque investido da entidade. Ao aplicar esse dispositivo de controle e composição de estoque, os gestores responsáveis pela área poderão controlar melhor os itens com o objetivo econômico de recursos financeiros frente à administração.

A atribuição monetária aos itens do estoque, pelo sistema $A B C$, dá maior segurança para a administração financeira da organização. Ao administrador, permite visualizar o estoque como um valor monetário e não apenas um espaço físico lotados de itens de matéria-prima em estoque.

O processo de tomada de decisões para gerenciamento dos estoques, quando embasados em controle eficientes, possibilita ao administrador uma maior assertividade em suas escolhas. Ao observar o estoque como um montante monetário com valores ali imobilizados e os itens com maior peso financeiro, as decisões tendem a ser tomadas com vistas a conseguir um maior retorno financeiro, pois seu ponto de referência foram os 


\section{ARTIGO DE REVISÃO I review article}

valores investidos em estoques e não apenas a quantidade física em estoque. Ao administrador, cabe observar e decidir a melhor opção de tomada de decisões para gerenciamento dos estoques de sua organização.

\section{REFERÊNCIAS}

[1]- VIANA, joão José. Administração de materiais: um enfoque prático.- 1 ed. -8 reimpr. São Paulo: Atlas, 2009.

[2]- ARNOLD, J. R. Tony. Administração de materiais. Tradução Celso Rimoli, Lenita R. Esteves.- 1. ed. -8. Reimpr.São Paulo: Atlas, 2009.

[3]- Moreira, Daniel Augusto. Administração da Produção e Operações. São Paulo:

Cengage Learning. 2a Ed. 2014.

[4]- DIAS, Marco Aurélio P.

Administração de materiais. 4. Ed.reimpr.-SP: Atlas, 2010.

[5]- POZO, Hamilton. Administração de recursos materiais e patrimoniais. 5 ed. - reimpr.- São Paulo: Atlas, 2009.

[6]- CORRÊA, Henrique L.; CORRÊA, Carlos A. Administração de produção e operações: manufatura e serviços: uma abordagem estratégica. -3. Ed. -São Paulo: Atlas, 2012.

[7]- SLACK, Nigel; CHAMBERS, Stuart; JOHNSTON, Robert. Administração da produção. Tradução Maria Teresa Corrêa de Oliveira.-3. Ed.-SP: Atlas, 2009.

[8]- Gil, Antonio Carlos. Como Elaborar Projetos de Pesquisa. São Paulo: Atlas 5ㄹ. Ed. 2010.
[9]- PARRA, domingos filho; SANTOS, joão almeida. Metodologia científica. São Paulo: futura, 2002.

[10]- PEREIRA, Moacyr. O uso da curva $A B C$ nas empresas. São Paulo.

Disponível em:< hyyp://kplus. cosmo. com. br/materia. asp>. Acesso em 24/08, v. 11, 1999. 